\title{
Impact Analysis of miR-1253 on Lung Cancer Progression Through Targeted Regulation of ANXA3
}

This article was published in the following Dove Press journal: Cancer Management and Research

\author{
Qiang Liu' \\ Shuai Wang' \\ Guotian Pei ${ }^{1}$ \\ Yingshun Yang' \\ Xianjun Min' \\ Yuqing Huang' \\ Jun $\mathrm{Liu}^{2}$ \\ 'Department of Thoracic Surgery, Beijing \\ Haidian Hospital, Beijing, 100000 , \\ People's Republic of China; ${ }^{2}$ Department \\ of Thoracic Surgery, Peking University \\ People's Hospital, Beijing, I00044, \\ People's Republic of China
}

Objective: This study set out to investigate the effect of $m i R-1253$ on lung cancer progression through targeted regulation of $A N X A 3$.

Methods: RT-PCR was employed to detect the miR-1253 expression levels in lung cancer cells and its targeted gene $A N X A 3$ mRNA determined by biological information prediction. MTT, invasion and apoptosis rate tests were employed to detect the proliferation, invasion and apoptosis rate of lung cancer cells over-expressing $m i R-1253$ or those with low expression of $A N X A 3$ and the expression of related proteins.

Results: RT-qPCR results manifested that the miR-1253 level was down-regulated in lung cancer tissues and cells, and the ANXA3 expression increased. The miR-1253 and ANXA3 expression levels were negatively correlated. $m i R-1253$ was correlated with tumor differentiation degree, TNM stage and lymph node metastasis of lung cancer patients. Cell tests confirmed that miR-1253 played a tumor-inhibiting function, including inhibiting proliferation and invasion of lung cancer cells and promoting apoptosis. Bioinformatics prediction and subsequent experiments proved that $A N X A 3$ was the direct target of miR-1253. Moreover, after the $A N X A 3$ expression in lung cancer cells was knocked down, proliferation and invasion of those cells were inhibited dramatically, the apoptosis rate increased markedly, and the expression levels of pro-apoptosis-related proteins Bax and caspase-3 were upregulated, and the anti-apoptosis-related protein $\mathrm{Bcl}-2$ expression was down-regulated.

Conclusion: $m i R-1253$ can inhibit the proliferation and invasion of lung cancer cells and promote their apoptosis by targeting $A N X A 3$. It can be used as a new potential target for lung cancer treatment.

Keywords: $m i R-1253$, lung cancer, $A N X A 3$, proliferation, invasion, apoptosis

\section{Introduction}

Lung cancer (LC), as one of the most frequent malignancies, is also one of the main types of cancer-induced death. ${ }^{1}$ In recent years, with the deterioration of the natural environment and the change of living habits, the morbidity of LC has become higher and higher, posing serious risks to human life and health. ${ }^{2}$ Although good advancement has been made in its diagnosis and treatment with the progress of medical technology recently, the prognosis of LC patients is still poor due to its rapid progression, high metastasis rate, high recurrence rate, etc. ${ }^{3,4}$ Therefore, it is quite significant to explore the pathogenesis and development mechanism of LC for its diagnosis and treatment clinically.

miRNA is a non-coding microRNA with a length of about $18-25$ nucleotides, which has been found to be effective in various diseases, especially tumors in the past. ${ }^{5}$ Previous 
studies ${ }^{6,7}$ have shown that miRNA can act as both cancerpromoting gene and tumor-suppressor gene in tumors. They have considered that miRNA imbalance plays a crucial part in the occurrence of tumors, having an impact on cell proliferation, invasion and apoptosis. However, many studies have been discussed on the role of miRNA in LC. For example, research $^{8}$ has found that $m i R-330-3 p$ can directly target $h S O D 2 b$ to advance LC cells' invasion, migration and metastasis. All these signify that miRNA plays an essential part in its occurrence and development. As a member of miRNA, miR1253 has also been reported to play a vital role in tumor in the past. For example, some studies ${ }^{9}$ have reported that $m i R-1253$ can regulate the proliferation and development of prostate cancer by targeting $\mathrm{EZH} 2$.

The latest research ${ }^{10}$ has shown that the miR-1253 expression level has high predictive value for the prognosis of LC patients. In order to analyze the mechanism of $m i R-1253$ in LC in depth, we found a targeted relationship between $m i R-1253$ and $A N X A 3$ through online website prediction, and further explored the mechanism of $m i R-1253$.

\section{Patients and Methods Clinical Data}

One hundred and two LC patients who underwent surgical treatment in our hospital from April 2015 to October 2016 were collected as research objects, including 62 male and 40 female patients. Through PCR test, we found that there were 40 Mycoplasma positive cases and 62 Mycoplasma negative cases. They were $(58.31 \pm 3.28)$ years old on average. One hundred and two cases of LC tissue and 102 cases of paracancerous tissue were obtained during the operation with patients' consent. Inclusion criteria: Patients diagnosed as LC by pathological diagnosis and those with an expected survival period over 3 months were included in the research group. Exclusion criteria: Patients with other malignancies, severe liver and kidney dysfunction, infection, blood or immune system disorders and those did not cooperate with the study were excluded. All patients and their families agreed to participate in the test and sign an informed consent form, and this test has been approved by The Third Affiliated Hospital of Peking University. This experiment conforms to the Declaration of Helsinki.

\section{Cell Culture and Transfection}

Human LC cell lines A549, H1299, H157, SPC-A-1 and human bronchial epithelial cell line (BEAS-2B) (ATCC) were cultured in RPMI 1640 medium containing 10\% fetal bovine serum (Gibco, USA), and the cells were cultured in a humid atmosphere at $37^{\circ} \mathrm{C}, 5 \% \mathrm{CO}_{2}$. Through the detection of $m i R-1253$ and $A N X A 3$ expression in cell lines, we found that the miR-1253 expression in A549 and H157 cell lines was lower than that in other two groups, so these two cell lines were chosen for transfection and subsequent experiments. The miR-1253-mimics, miR-1253-Inhibitor, miR-NC, $A N X A 3$ small interfering RNA (siRNA) (Si$A n x A 3)$ and its negative control (si-NC) were transfected into cells by Lipofectamine 2000 kit (Invitrogen, Carlsbad, USA), and the operation steps were strictly conducted based on the kit instructions.

\section{RT-PCR Detection}

The total RNA in the tissue was extracted with Trizol reagent (Invitrogen, USA), and its purity and concentration were detected by ultraviolet spectrophotometer. Then, every $5 \mu \mathrm{g}$ of total RNA was taken, respectively, to reversely transcribe cDNA based on the instructions of the kit (TaKaRa, Dalian, China). Amplification conditions were as follows: PCR reaction conditions: pre-denaturation at $94^{\circ} \mathrm{C}$ for $30 \mathrm{~s}$, denaturation at $94^{\circ} \mathrm{C}$ for $5 \mathrm{~s}$, annealing extension at $60^{\circ} \mathrm{C}$ for $30 \mathrm{~s}$, a total of 40 cycles. miR1253 employed $U 6$ as internal reference, $A N X A 3$ employed GAPDH as internal reference, and data were analyzed by. ${ }^{-\Delta \Delta c t 11}$ The primer sequences are shown in Table 1.

\section{Cell Proliferation Was Detected via MTT Assay}

Based on the instructions of MTT Kit (Beyotime Biotechnology Co., Ltd.), LC cell lines transfected for 48 $\mathrm{h}$ were inoculated into 96-well plates, each well was inoculated with about 5000 cells with a cell density of $3 \times 10^{4}$ cell $/ \mathrm{mL}$, and then incubated at $37^{\circ} \mathrm{C}$. Altogether 10 $\mu \mathrm{L}$ of MTT solution was supplemented to each well for 24 , 48, 72 and $96 \mathrm{~h}$, respectively. After the reagents were added, the cells were continuously cultured $4 \mathrm{~h}$ in an incubator, and then $150 \mu \mathrm{L}$ of dimethyl sulfoxide was supplemented. After they were shaken for $10 \mathrm{~min}$, the absorbance was surveyed at $490 \mathrm{~nm}$ using an enzyme reader to detect cell proliferation. This test was repeated three times.

\section{Cell Invasion Detection (Transwell)}

Cells transfected for $24 \mathrm{~h}$ were collected, adjusted to $3 \times 10^{5}$ cell $/ \mathrm{mL}$ and inoculated on a 6 -well plate, and 
Table I Primer Sequence Table

\begin{tabular}{|l|l|l|}
\hline Factors & Upstream Primer 5'-'3 & Downstream Primer 5'-'3 \\
\hline miR-1253 & GCTGTAACAGCGGCGGAACTCC & ATCCGCAGGAGTGTCCGAG \\
\hline U6 & GCTTCGGCAGCACATATACTAAAAT & CGCTTCACGAATTTGCGTGTCAT \\
\hline $\begin{array}{l}\text { ANXA3 } \\
\text { GAPDH }\end{array}$ & $\begin{array}{l}\text { ACAGCGGCAGCTGATTGTTA } \\
\text { GGATATTGTTGCCATCAATGACC }\end{array}$ & $\begin{array}{l}\text { TCACTAGGGCCACCATGAGA } \\
\text { AGCCTTCTCCATGGTGGTGAAGA }\end{array}$ \\
\hline
\end{tabular}

inoculation and upper chamber were washed with PBS twice. Altogether $200 \mu \mathrm{L}$ DMEM culture solution was supplemented to the upper chamber, and $500 \mathrm{~mL}$ of DMEM containing $20 \% \mathrm{FBS}$ was supplemented to the lower chamber. Substrates and cells in the upper chamber that did not cross over the membrane surface were wiped off after culturing at $37^{\circ} \mathrm{C}$ for $48 \mathrm{~h}$ and cleaned 3 times with PBS. Then, they were fixed $10 \mathrm{~min}$ by paraformaldehyde, washed 3 times with double-distilled water, and stained by $0.5 \%$ crystal violet after drying. Finally, cell invasion was observed by a microscope.

\section{Apoptosis Test}

Cells were digested with $0.25 \%$ trypsin, cleaned twice with PBS after digestion, supplemented with $100 \mu \mathrm{L}$ of binding buffer, prepared into $1 \times 10^{6} / \mathrm{mL}$ suspension, sequentially supplemented with AnnexinV-FITC and PI, incubated $5 \mathrm{~min}$ at room temperature in dark, and detected with FC500MCL flow cytometer system. We repeated this experiment 3 times and took the average value.

\section{Western Blot Test}

Total protein was extracted from the collected and cultured cells of each group via RIPA lysis method (Thermo Fisher, USA). Protein concentration was detected through BCA method and adjusted to $4 \mu \mathrm{g} / \mu \mathrm{L}$. It was separated by $12 \%$ SDS-PAGE electrophoresis and then transferred to a PVDF membrane. The membrane was dyed with Ponceau S working solution, immersed 5 min in PBST (PBS+0.1\%Tween 20) and then washed, blocked $2 \mathrm{~h}$ with $5 \%$ defatted milk powder, and finally blocked all night long at $4^{\circ} \mathrm{C}$ with $\operatorname{Bax}(1: 500), B c l-2$ (1:500), caspase-3 (1:500), ANXA3 (1:1000) and $\beta$-Actin primary antibody (1:1000) (Cell Signaling Technology). It was washed to remove primary antibody. Horseradish peroxidase-labeled goat anti-rabbit secondary antibody (1:1000) (Abcam, USA) was supplemented to the membrane for a 1-hour incubation at $37^{\circ} \mathrm{C}$. Soon afterwards, it was cleaned 3 times with PBS, for 5 min each time. Ultimately, it was developed in a darkroom by the enhanced chemiluminescence reagent (ECL), and its excess liquid was absorbed with a filter paper.

\section{Dual-Luciferase Reporter Enzyme}

Dual-luciferase reporter gene assay was conducted to test whether $A N X A 3$ was a direct target gene of miR-1253. $A N X A 3$ 3'UTR dual-luciferase reporter plasmids (WT and MUT) were constructed via RiboBio. They were cotransfected into cells with miR-1253 mimics or mimetic control, respectively, via Lipofectamine 2000. Forty-eight hours after incubation, luciferase activity was tested via a dual-luciferase assay system (Promega Corporation).

\section{Statistical Methods}

In this research, data were processed by SPSS 20.0 software, and relevant pictures were drawn by GraphPad Prism 6 software. The measurement data were presented as mean \pm standard deviation ( $\mathrm{SD} \pm$ meas) and checked through $t$ test. Inter-group comparison was under independent-samples $t$ test and expressed as t. Multi-group comparison was under one-way analysis of variance. Post hoc pairwise comparison was under LSD- $t$ test. Multi-time point expression was under repeated measures analysis of variance. Backtesting adopted Bonferroni and correlation analysis adopted Pearson. $\mathrm{P}<0.05$ was seen as statistical difference.

\section{Results}

\section{Expression and Clinical Significance of miR- 1253 and ANXA3 in LC}

The miR-1253 and ANXA3 mRNA levels were detected by qRT-PCR. The results revealed that the miR-1253 expression in LC tissues was dramatically lower than that in paracancerous tissues $(\mathrm{P}<0.05)$, and the $A N X A 3$ mRNA expression was dramatically higher than that in paracancerous tissues $(\mathrm{P}<0.05)$. The miR-1253 expression in LC cell line was 
lower than that of BEAS-2B cell line $(\mathrm{P}<0.05)$, and the $A N X A 3$ expression in LC cell line was higher than that of BEAS-2B cell line $(\mathrm{P}<0.05)$. Correlation analysis manifested that the miR-1253 and $A N X A 3$ expression levels in LC tissue were negatively correlated $(\mathrm{P}<0.05)$. ROC curve analysis revealed that the AUC of miR-1253 for LC's diagnosis was 0.892 . According to the mean expression of miR1253, patients were divided into high expression group (43 cases) and low expression group (59 cases). Further analysis of the relationship between miR-1253 and pathological data signified that miR-1253 was relevant to tumor differentiation, TNM stage and lymph node metastasis of LC patients $(\mathrm{P}<0.05)$. (Figure 1, Table 2)

\section{miR-I 253's Effect on Biological Function of LC Cells}

To study miR-1253' effect on proliferation, invasion and apoptosis of LC cells, A549 and H157 cells were transfected with miR-1253-mimics, miR-1253-inhibitor and miR-NC. Forty-eight hours after transfection, compared with miR-NC, miR-1253 in the two cells transfected with miR-1253 mimic increased obviously $(\mathrm{P}<0.05)$, and the $m i R-1253$ expression in cells transfected with miR-NC decreased obviously $(\mathrm{P}<0.05)$. In addition, MTT assay, cell invasion and flow apoptosis assay were performed after transfection. The results showed that the $m i R-1253$ over-expression greatly inhibited proliferation $(\mathrm{P}<0.05)$ and invasion $(\mathrm{P}<0.05)$ of $\mathrm{A} 549$ and $\mathrm{H} 157$ cells, and promoted apoptosis. And WB experiment confirmed that the pro-apoptotic protein Bax and caspase-3 protein expression levels in cells increased, and the anti-apoptotic protein $B c l-2$ expression was down-regulated $(\mathrm{P}<0.05)$. The proliferation and invasion of cells transfected with miR1253-inhibitor were markedly enhanced, the apoptosis rate decreased dramatically $(\mathrm{P}<0.05)$, and the pro-apoptotic protein Bax and caspase-3 protein expression levels decreased, while the anti-apoptotic protein $\mathrm{Bcl}-2$ expression was up-regulated $(\mathrm{P}<0.05)$. (Figure 2$)$

\section{Effect of Down-Regulation of ANXA3 Expression on Biological Function of LC Cells}

In order to confirm whether the tumor inhibitory effect of $m i R-1253$ in LC was mediated by $A N X A 3$, we knocked down the ANXA3 expression in A549 and H157 cells. Western blot analysis identified that after transfection
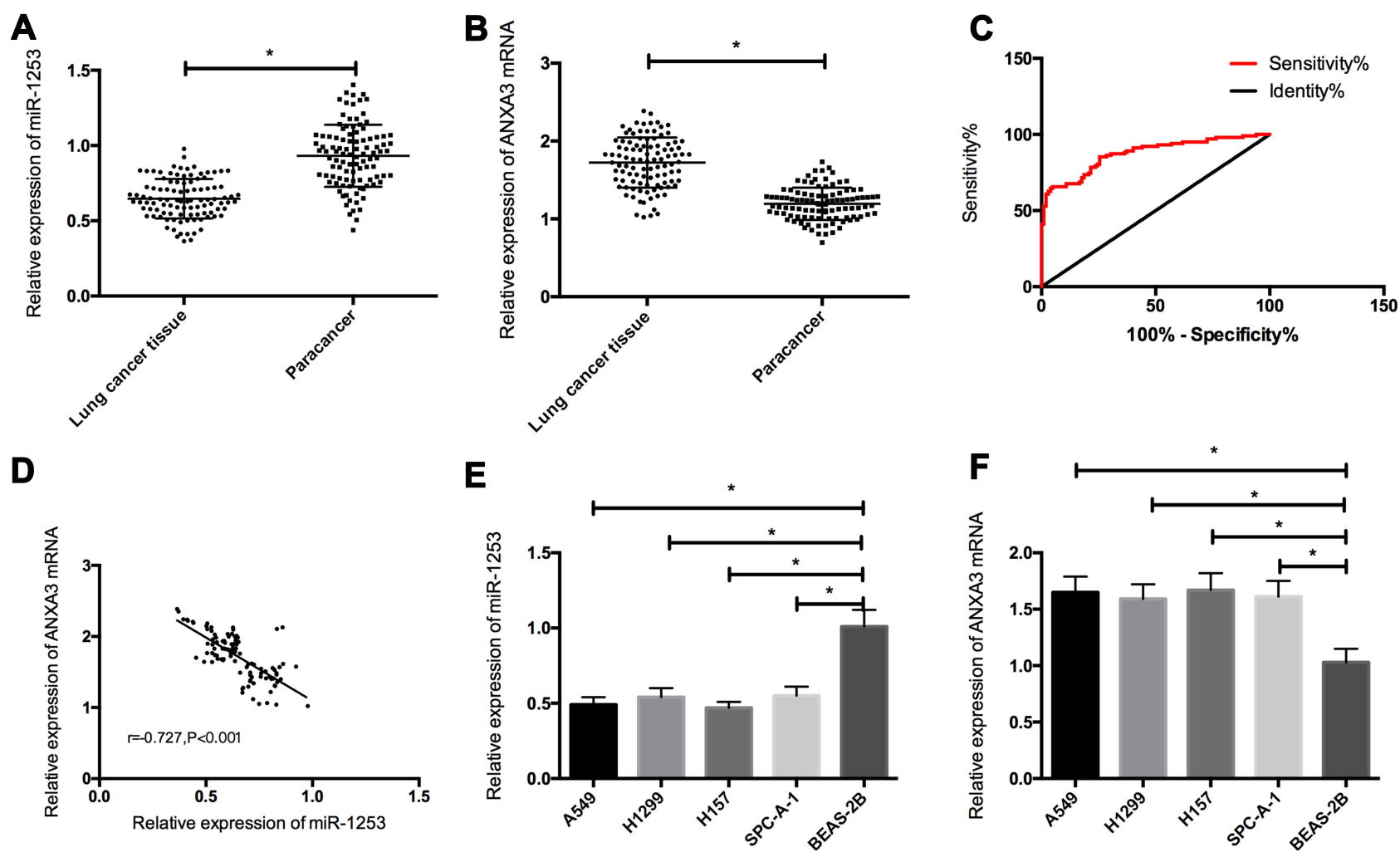

Figure I Expression and clinical significance of miR-/253 and ANXA3 in LC. (A) miR-/253 expression in LC tissues. (B) ANXA3 expression in LC tissues. (C) ROC of miR1253 in diagnosing LC. (D) Correlation analysis between miR-I 253 and ANXA3. (E) miR- $/ 253$ expression in LC cells. (F) ANXA3 expression in LC cells. * Indicates P<0.05. 
Table 2 Relationship Between miR-I 253 and Clinicopathological Data of LC Patients

\begin{tabular}{|c|c|c|c|c|c|}
\hline \multirow[t]{2}{*}{ Factors } & & \multicolumn{2}{|l|}{ miR-I253 } & \multirow[t]{2}{*}{$x^{2}$ value } & \multirow[t]{2}{*}{$P$ value } \\
\hline & & Low Expression $(n=59)$ & High Expression $(n=43)$ & & \\
\hline \multirow[t]{2}{*}{ Age } & $\geq 58$ years old $(n=53)$ & 31 (52.54) & $22(51.16)$ & \multirow[t]{2}{*}{0.019} & \multirow[t]{2}{*}{0.891} \\
\hline & $<58$ years old $(n=49)$ & $28(47.46)$ & $21(48.84)$ & & \\
\hline \multirow[t]{2}{*}{ Gender } & Male $(n=62)$ & $37(62.71)$ & $25(58.14)$ & \multirow[t]{2}{*}{0.218} & \multirow[t]{2}{*}{$0.64 I$} \\
\hline & Female $(n=40)$ & $22(37.29)$ & $18(41.86)$ & & \\
\hline \multirow[t]{2}{*}{ TNM stage } & Stages I-II $(n=57)$ & 22 (37.29) & $35(81.40)$ & \multirow[t]{2}{*}{19.63} & \multirow[t]{2}{*}{$<0.001$} \\
\hline & Stages III $(n=45)$ & $37(62.71)$ & $8(18.60)$ & & \\
\hline \multirow[t]{2}{*}{ Differentiation } & Low differentiation $(n=63)$ & $50(84.75)$ & $13(30.23)$ & \multirow[t]{2}{*}{31.30} & \multirow[t]{2}{*}{$<0.001$} \\
\hline & Moderate + high differentiation $(n=39)$ & $9(15.25)$ & $30(69.77)$ & & \\
\hline \multirow[t]{2}{*}{ Lymphatic metastasis } & Metastasis $(n=37)$ & $28(47.46)$ & $9(20.93)$ & \multirow[t]{2}{*}{7.572} & \multirow[t]{2}{*}{0.001} \\
\hline & No metastasis $(n=65)$ & $31(52.54)$ & $34(79.07)$ & & \\
\hline \multirow[t]{2}{*}{$\begin{array}{l}\text { Mycoplasma } \\
\text { infection }\end{array}$} & Positive $(n=40)$ & $23(38.98)$ & $17(39.53)$ & \multirow[t]{2}{*}{0.003} & \multirow[t]{2}{*}{0.955} \\
\hline & Negative $(n=62)$ & $36(61.02)$ & $26(60.47)$ & & \\
\hline
\end{tabular}

with si- $A N X A 3, A N X A 3$ was down-regulated in A549 and H157 cells $(\mathrm{P}<0.05)$. After transfection, MTT assay and cell invasion assay manifested that si-ANXA3 remarkably inhibited the proliferation and invasion of A549 and H157 cells and promoted their apoptosis $(\mathrm{P}<0.05)$. WB experiment revealed that the pro-apoptotic proteins Bax and caspase-3 expression levels increased and the antiapoptotic protein $B c l-2$ expression decreased in the cells knocked down the ANXA3 expression. These results further indicated that $A N X A 3$ was the direct functional target of miR-1253 in LC (Figure 3).

\section{Dual-Luciferase Reporter Enzyme}

In order to explore miR-1253's potential mechanism in LC, bioinformatics analysis was conducted to predict the target gene of miR-1253. ANXA3 was identified as its target gene. Luciferase reporter gene assay was conducted to check whether the 3'UTR of $A N X A 3$ could be directly targeted by $m i R-1253$. The results revealed that the $m i R$ 1253 over-expression decreased the luciferase activity of
ANXA3 3' UTR Wt $(\mathrm{P}<0.05)$, but had no effect on ANXA3 $3^{\prime}$ UTR Mut. What is more, Western blot showed that the ANXA3 protein expression in A549 and $\mathrm{H} 157$ cells mock transfected with miR-1253 was down-regulated, but in LC cells transfected with miR-1253-inhibitor, it was markedly up-regulated $(\mathrm{P}<0.05)$. (Figure 4)

\section{Rescue Experiment}

Through co-transfection of miR-1253-inhibitor+si-ANXA3 to A549 and $\mathrm{H} 157$ cells, their proliferation, invasion and apoptosis were detected. The results signified that the three of transfected miR-1253-inhibitor+si-ANXA3 cells were not different from those of transfected miR-NC cells, while those were dramatically enhanced and decreased compared with those of transfected si-ANXA3 cells, which indicated that $m i R-1253$-inhibitor could reverse the effect of si-ANXA3 on LC cells. WB detection revealed that the Bax, caspase- 3 , and Bcl-2 expression levels in transfected miR-1253-inhibitor+si-ANXA3 cells were not different from those in transfected miR-NC cells, and the 

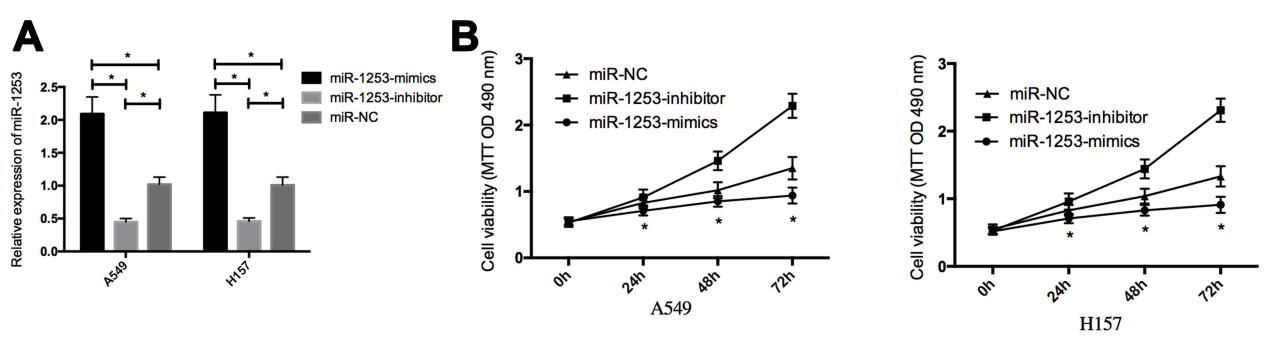

C

D
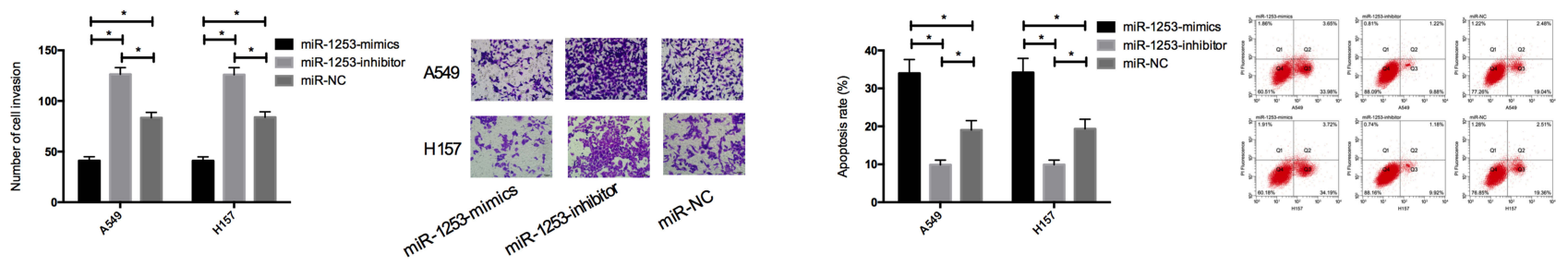

E
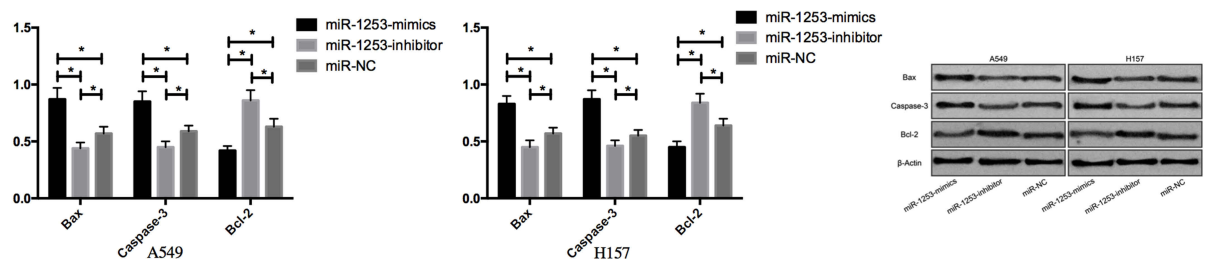

Figure 2 Effect of miR-I 253 on proliferation, invasion and apoptosis of LC cells. (A) miR-/253 expression in LC cells after transfection. (B) Effect of miR-/253 on proliferation of LC cells. (C) Effect of miR-I 253 on invasion ability of LC cells. (D) Effect of miR-I 253 on apoptosis of LC cells. (E) Effect of miR-I 253 on apoptosis-related cells in LC cells. ${ }^{*}$ Indicates $\mathrm{P}<0.05$.

$B c l-2$ protein expression was obviously higher than that in transfected si-ANXA3 cells, while the Bax protein and caspase-3 protein expression levels were dramatically lower $(\mathrm{P}<0.05)$. (Figure 5)

\section{Discussion}

LC is the principal reason for cancer-related death all over the world currently, and the mechanism of its occurrence and development has always been the focus of medical research. ${ }^{12}$ Although advances in medical technology in recent years have enabled people to have a certain understanding of the development of LC, it is impossible to accurately evaluate every process of its development. ${ }^{13}$ miRNA's important role in tumors has been continuously verified and confirmed, including LC. For instance, research $^{14}$ found that miR-203 could inhibit their proliferation, invasion and migration by down-regulating RGS17. Therefore, the analysis of miRNA's influence on LC progression has momentous clinical significance for the diagnosis and treatment of patients.

miR-1253 has been found to act as a tumor-suppressor gene in some tumors. For example, research ${ }^{15}$ found that inhibiting miR-1253 expression could promote the development of prostate cancer. In our study, we first found that the miR-1253 expression in LC tissues and cells was dramatically down-regulated, and further analyzed its clinical significance. We found that miR-1253 had high diagnostic value for $\mathrm{LC}$, and its expression was bound up with the pathological stage, differentiation degree and lymph node metastasis of patients. This further indicates that miR-1253 may be crucial in LC's occurrence and development. Rapid development, high recurrence and metastasis of LC usually lead to poor prognosis, so it is quite significant for those patients to know how to inhibit its progression. ${ }^{16,17}$ Therefore, in order to observe miR1253's effect on the progression of LC, we regulated the $m i R-1253$ expression in those cells and observed their changes after the regulation of $m i R-1253$. We observed that when we over-expressed miR-1253 in LC cells, their proliferation and invasion were obviously inhibited, but the apoptosis rate increased dramatically. Bax and Bcl-2 belong to the BCL family; previous studies ${ }^{18}$ showed that increased Bax expression might induce apoptosis, while increased $\mathrm{Bcl}-2$ expression might inhibit apoptosis. Caspase-3 belongs to the cysteine protease family, which is the main effector in the process of apoptosis; its 


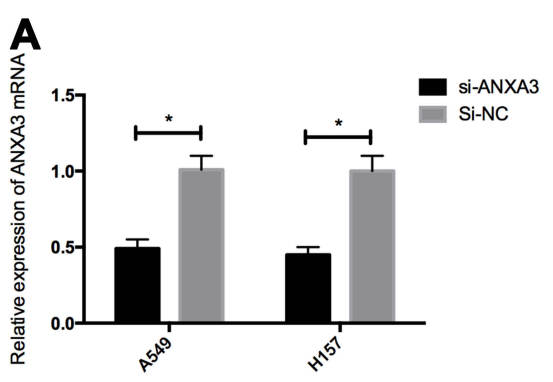

B
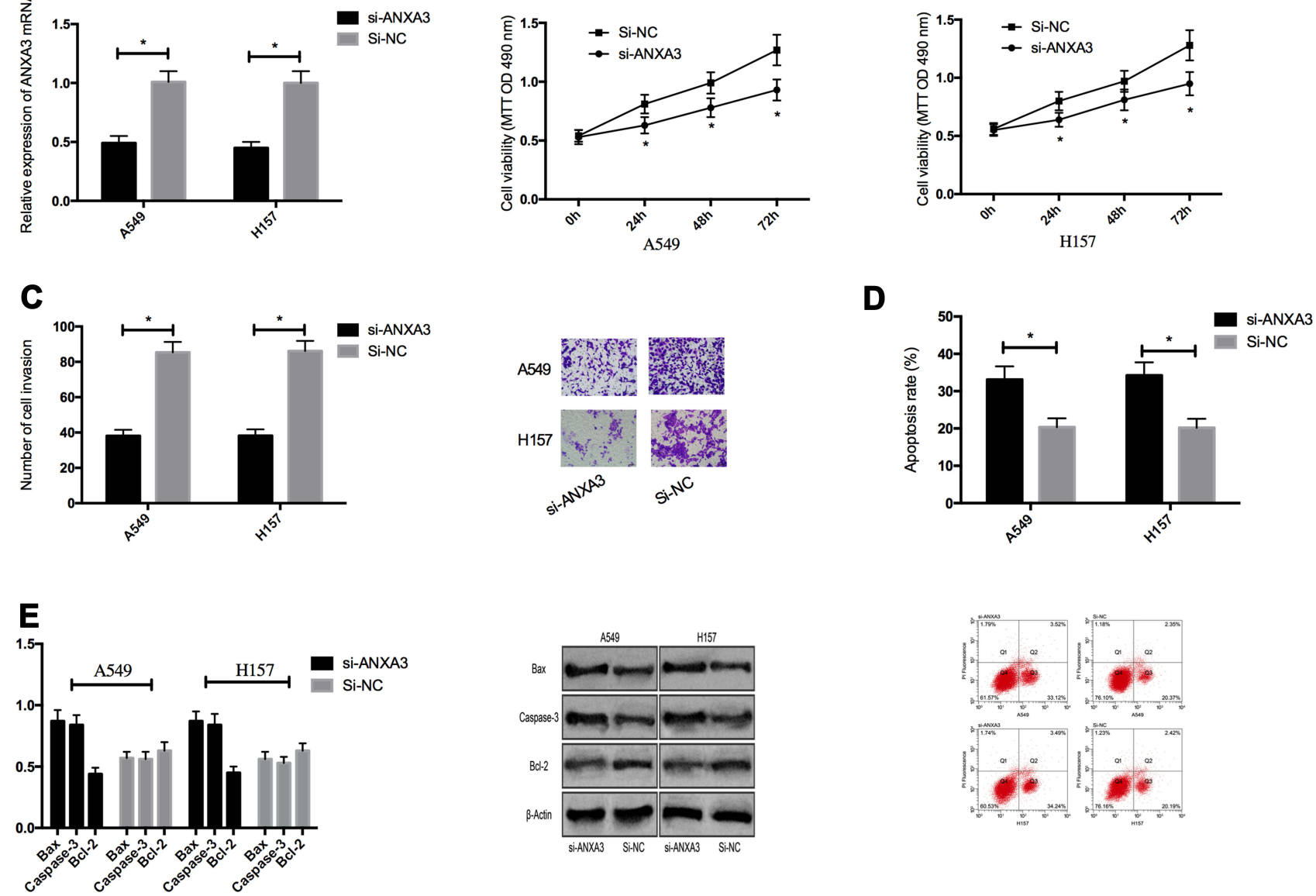

Figure 3 Effect of downregulation of ANXA3 expression on proliferation, invasion and apoptosis of LC cells. (A) ANXA3 expression in LC cells after transfection. (B) Effect of ANXA3 on proliferation of LC cells. (C) Effect of ANXA3 on the invasive ability of LC cells. (D) Effect of ANXA3 on apoptosis of LC cells. (E) Effect of ANXA3 on apoptosisrelated cells in LC cells. * Indicates $\mathrm{P}<0.05$.

A

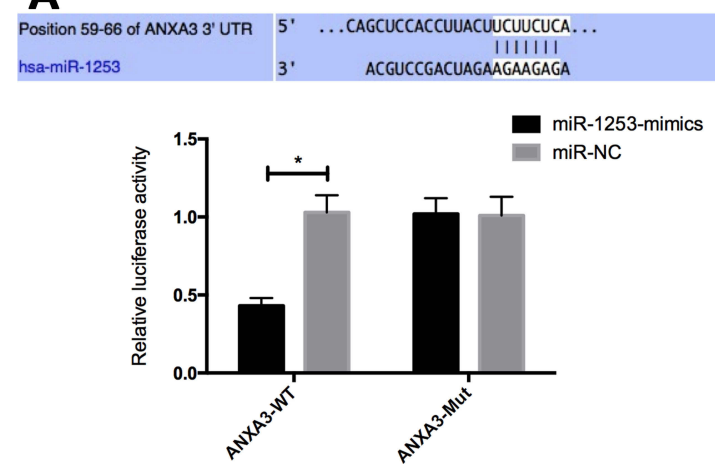

B

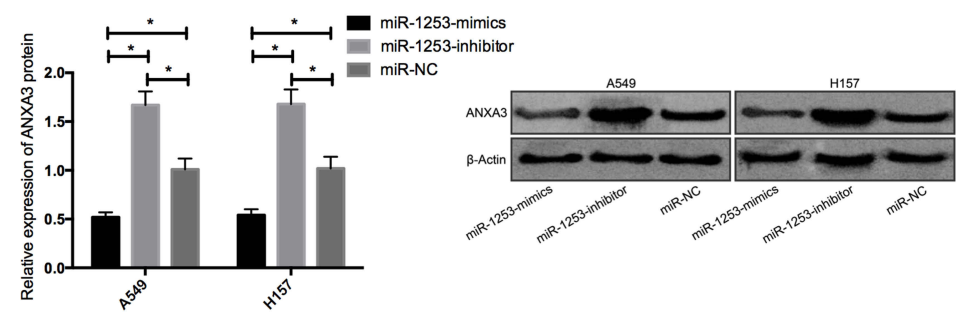

Figure 4 Dual-luciferase reporter enzyme. (A) Effect of miR-I 253 on ANXA3 dual-luciferase reporter enzyme activity. (B) Effect of miR-I253 on ANXA3 protein expression. * Indicates $\mathrm{P}<0.05$.

activation marks the irreversibility of apoptosis. ${ }^{19}$ The changes of apoptosis-related proteins were consistent with the trend of apoptosis rate. However, when we further inhibited the miR-1253 expression, we observed the opposite cell phenotype. This suggested that miR-1253 could inhibit the development of tumor cells and promote their apoptosis. In the past, its role in tumor was also found to be a tumor-suppressor gene. For example, research ${ }^{20}$ found that $m i R-1253$ could inhibit the malignant behavior of osteosarcoma by regulating FOXF1. Another study ${ }^{21}$ 

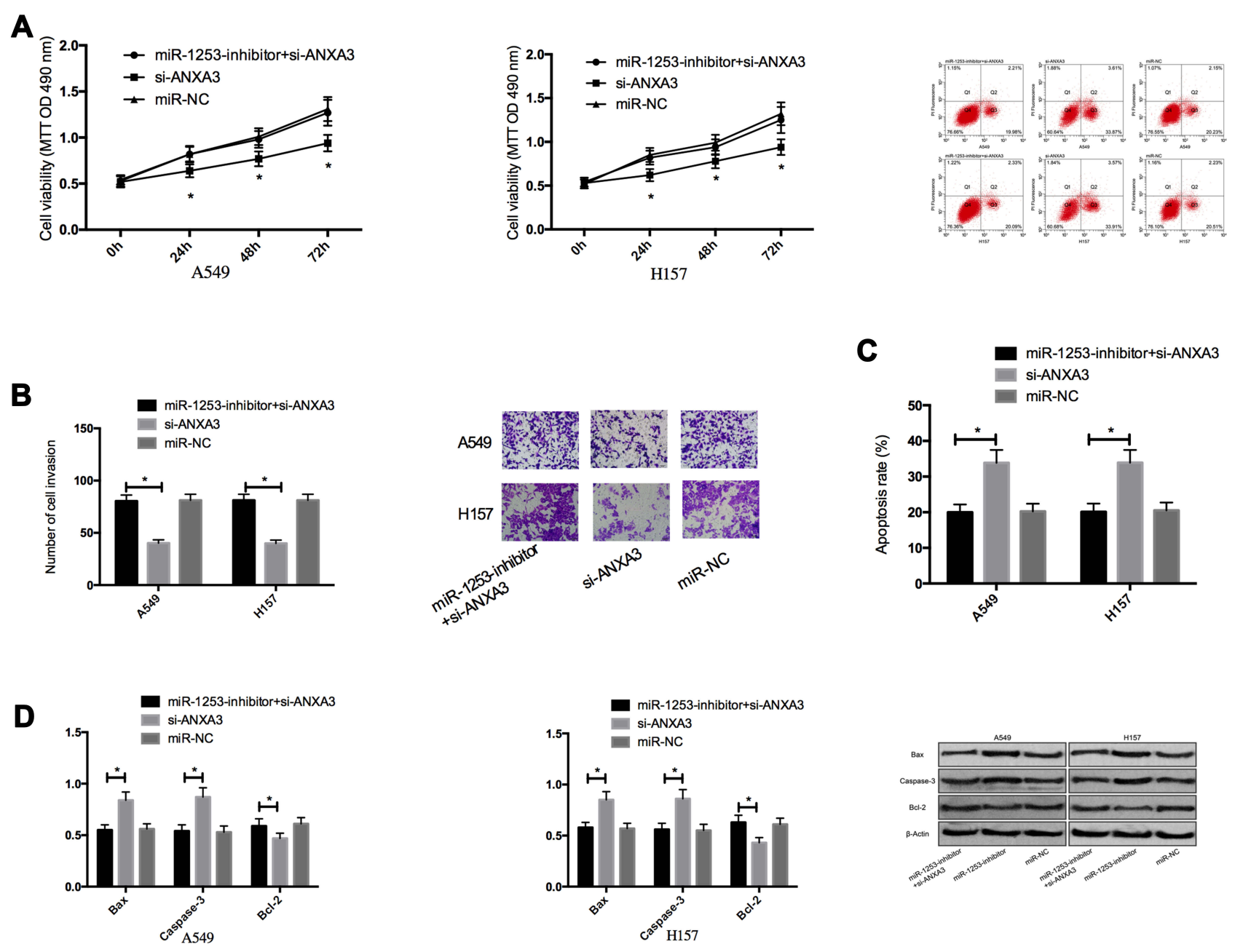

Figure 5 Rescue experiment. (A) Effect of miR-/253-inhibitor+si-ANXA3 on proliferation of LC cells. (B) Effect of miR-/253-inhibitor+si-ANXA3 on invasion ability of LC cells. (C) Effect of miR-I253-inhibitor+si-ANXA3 on apoptosis rate of LC cells. (D) Effect of miR-I253-inhibitor+si-ANXA3 on apoptosis-related proteins in LC cells. * Indicates $\mathrm{P}<0.05$.

discovered that inhibiting $m i R-1253$ could promote the progression of pancreatic ductal adenocarcinoma cells. This was consistent with the role of miR-1253 found in LC.

It is well known that miRNA affects cell function by binding its target genes. ${ }^{22}$ Previous studies ${ }^{23}$ have also pointed out that $m i R-1253$ can inhibit proliferation and invasion of non-small cell LC by targeting WNT5A, which is consistent with $m i R-1253$ 's effect on LC cells found in the above studies. However, each miRNA has more than one target gene. We found that $A N X A 3$ was also the direct target of $m i R-1253$ through bioinformatics prediction. It is a member of the annexin family, which can be combined with calciumdependent acidic phospholipids. ${ }^{24}$ Previous studies have indicated that $A N X A 3$ is essential in the occurrence and development of tumors. ${ }^{25}$ For example, it is reported that $A N X A 3$ is a potential biomarker in bladder cancer ${ }^{26}$ and gastric cancer. ${ }^{27}$
In our work, we found that the $A N X A 3$ expression in LC tissues and cells increased markedly, which signified that it might act as cancer-promoting gene in LC. Previously, the role of $A N X A 3$ in tumors was also found to be increased in expression, and some studies ${ }^{28}$ also found that the $A N X A 3$ expression in LC cells was dramatically higher than that in normal cells, which was consistent with our detection results. Previously, some studies ${ }^{29}$ have found that RNA interference silencing the expression of $A N X A 3$ can inhibit the proliferation and invasion of breast cancer cells, and ${ }^{30}$ other studies have pointed out that the increased expression of $A N X A 3$ will further enhance the tumorigenicity of liver cancer cells, which is consistent with our observation of the role of $A N X A 3$ in lung cancer. Subsequently, in order to observe $A N X A 3$ 's effect on LC cells in depth, we down-regulated the $A N X A 3$ expression in those cells. The results revealed that when we down-regulated its expression, their proliferation and invasion were 
dramatically inhibited, and the apoptosis rate increased dramatically. This also confirmed that $A N X A 3$ acted as an oncogene in LC. Soon afterwards, in order to verify the targeted relationship between miR-1253 and $A N X A 3$, we conducted dual-luciferase reporter enzyme experiments and rescue experiments. The results confirmed that there was indeed a targeted relationship between miR-1253 and $A N X A 3$, and miR-1253-inhibitor could reverse the effect of si- $A N X A 3$ on LC cells, and further demonstrated that miR-1253 influenced the development of LC by regulating ANXA3.

\section{Conclusion}

miR-1253 is low expressed in lung cancer and acts as a tumor-suppressor gene. The specific mechanism may be achieved by regulating the $A N X A 3$, which may be a potential target for lung cancer treatment, which also provides a new target. There are still some inadequacies in this study. For example, first of all, we have yet to prove the effect of $m i R-1253$ on tumor growth through in vivo tumor-forming tests. Secondly, we are still not clear about the downstream mechanism of $A N X A 3$. Hence, we will carry out further basic experiments on this in future studies in order to provide more data support for our conclusions.

\section{Acknowledgment}

This work was supported by the General Program Fund of Haidian Section of Peking University Third Hospital (KYM2017015).

\section{Disclosure}

The authors report no conflicts of interest in this work.

\section{References}

1. Chen Z, Fillmore CM, Hammerman PS, Kim CF, Wong KK. Nonsmall cell lung cancer: multiple diseases. Rev Nat. 2014;14 (8):535-546. doi:10.1038/nrc3775

2. Wood SL, Pernemalm M, Crosbie PA, Whetton AD. Role of tumor microenvironment in lung cancer metastasis and its relationship with potential therapeutic targets. Cancer Treatment. 2014;40(4):558-566. doi:10.1016/j.ctrv.2013.10.001

3. $\mathrm{Wu} \mathrm{H}$, et al. Circulating exosomes microRNA-96 promotes cell proliferation, migration, and drug resistance by targeting LMO7. J Cell Molecules Medium. 2017;21(6):1228-1236. doi:10.1111/jcmm.13056

4. Sertaç Y, Sevtün S, Berker Ö, et al. Oxygen uptake efficiency slope and prediction of post-operative morbidity and mortality in patients with lung cancer. Lung. 2018;196:255-262. doi:10.1007/s00408-018-0085-y

5. ElKhouly Aisha M, Youness RA, Gad MZ. MicroRNA-486-5p and microRNA-486-3p: multifaceted pleiotropic mediators in oncological and non-oncological conditions. Noncoding RNA Res. 2020;5 (1):11-21. doi:10.1016/j.ncrna.2020.01.001

6. Jianhua L, Junsu P, Yan J, et al. MiR-195-5p inhibits proliferation and induces apoptosis of non-small cell lung cancer cells by targeting CEP55. Onco Targets Ther. 2019;12:11465-11474.
7. Wenjing Q, Chengshun G, Li Z, et al. MiR-3196, a p53-responsive microRNA, functions as a tumor suppressor in hepatocellular carcinoma by targeting FOXP4. Am J Cancer Res. 2019;9(12):2665-2678.

8. Lianghua S, Shanze Y, Luyuan H, et al. miR-330-3p promotes lung cancer cells invasion, migration, and metastasis by directly targeting hSOD2b. Biotechnol Appl Biochem. 2019;66(1):21-32. doi:10.1002/ bab.1691

9. Yanbo C, Meng. Long noncoding RNA FOXC2-AS1 facilitates the proliferation and progression of prostate cancer via targeting miR-1253/EZH2. Gene. 2018.

10. Gasparini P, Cascione L, Landi L, et al. microRNA classifiers are powerful diagnostic/prognostic tools in ALK-, EGFR-, and KRAS-driven lung cancers. Procedure Natl Coll Sci USA. 2015;112 (48):14924-14929. doi:10.1073/pnas.1520329112

11. Tuomi JM, Voorbraak F, Jones DL, et al. The deviation of the Cq value observed by the quantitative probe-based PCR can be corrected by the estimated PCR efficiency value. Methods. 2010;50 (4):313-322. doi:10.1016/j.ymeth.2010.02.003

12. Byung-Seok K, Jelita C, Qing W, et al. Targeting ST2 expressing activated regulatory $\mathrm{T}$ cells in Kras-mutant lung cancer. Oncoimmunology. 2020;9:1682380. doi:10.1080/2162402X.2019.1682380

13. Harris CL, Toloza EM, Klapman JB, et al. Minimally invasive mediastinal staging of non-small cell lung cancer: focus on ultrasound-guided fine needle aspiration. Cancer Control. 2014;21:15-20. doi:10.1177/107327481402100103

14. Yongbin C, Qinqin J, Xinghui L, et al. miR-203 inhibits cell proliferation, invasion, and migration of non-small-cell lung cancer by downregulating RGS17. Cancer Sci. 2017;108:2366-2372. doi:10.1111/cas.13401

15. Yanbo C, Meng G, Chong L, et al. Long noncoding RNA FOXC2-AS1 facilitates the proliferation and progression of prostate cancer via targeting miR-1253/EZH2. Gene. 2019;686:37-42. doi:10.1016/j.gene.2018.10.085

16. Herbst RS, Prager D, Hermann R, et al. TRIBUTE: a Phase III clinical trial of erlotinib hydrochloride (OSI-774) combined with carboplatin and paclitaxel for advanced non-small cell lung cancer. $J$ Clinical Oncol. 2005;23(25):5892-5899. doi:10.1200/JCO.2005.02.840

17. Rota M, Pizzato M, La Vecchia C, et al. Efficacy of lung cancer screening appears to increase with prolonged intervention: results from the MILD trial and a meta-analysis. Ann Oncol. 2019;30:1040-1043. doi:10.1093/annonc/mdz145

18. Zheng JH, Follis Viacava A, Kriwacki RW, Moldoveanu T. Discovery and controversy of BCL-2 protein-mediated apoptosis. FEBS J. 2016;283(14):2690-2700. doi:10.1111/febs.13527

19. Fiandalo MV, Kyprianou N. Caspase control: protagonist of cancer cell apoptosis. Exp Oncol. 2012;34(3):165-175.

20. Lipeng H, Mangmang C, Jun P, et al. Circular RNA circNASP modulates the malignant behaviors in osteosarcoma via miR-1253/ FOXF1 pathway. Biochem Biophys Res Commun. 2018;500 (2):511-517. doi:10.1016/j.bbrc.2018.04.131

21. Yi X, Yue Y, Ping G, et al. Upregulated circular RNA circ_0030235 predicts unfavorable prognosis in pancreatic ductal adenocarcinoma and facilitates cell progression by sponging miR-1253 and miR-1294. Biochem Biophys Res Commun. 2019;509:138-142. doi:10.1016/j. bbrc.2018.12.088

22. Saeed N, Elham B, Maleki Leili A, et al. Restoration of miR-193a-5p and miR-146 a-5p expression induces G1 arrest in colorectal cancer through targeting of MDM2/p53. Adv Pharm Bull. 2020;10 (1):130-134. doi:10.15171/apb.2020.017

23. Meiyue L, Yue Z, Jie Z, et al. MicroRNA-1253 suppresses cell proliferation and invasion of non-small-cell lung carcinoma by targeting WNT5A. Cell Death Dis. 2018;9(2):189. doi:10.1038/s41419017-0218-x

24. Perron B, Lewit-Bentley A, Geny B, Russo-Marie F. Is it possible to infer enzyme activity from the structural studies of Annexin III? J Biochem. 1997;272:11321-11326. 
25. Yang L, Men W-L, Yan K-M, et al. MiR-340-5p is a potential prognostic indicator of colorectal cancer and modulates ANXA3. Eur Rev Med Pharmacol Sci. 2018;22(15):4837-4845. doi:10.26355/ eurrev_201808 15619

26. Cai $\mathrm{CH}$, Chen YT, Chang YH, et al. Systematic validation of tissue protein biomarker candidates related to bladder cancer in clinical urine samples. Oncotarget. 2018;9(56):30731-30747. doi:10.18632/ oncotarget. 24578

27. Wang K, Li J. ANXA3 overexpression is an independent prognostic indicator of gastric cancer, and its consumption inhibits cell proliferation and tumor growth. Oncotarget. 2016;7:86972-86984.
28. Limin W, Xueqin L, Yinghui R, et al. Cancer-associated fibroblasts contribute to cisplatin resistance by modulating ANXA 3 in lung cancer cells. Cancer Sci. 2019;110(5):1609-1620. doi:10.1111/ cas. 13998

29. Zhou T, Li Y, Yang L, et al. Silencing of ANXA3 expression by RNA interference inhibits the proliferation and invasion of breast cancer cells. Oncol Rep. 2016.

30. Tong M, Ma S. Secretory ANXA3 endows liver cancer cells with tumorigenic and self-renewal abilities and promotes HCC development. Cancer Res. 2015;75(15 Supplement):3946. doi:10.1158/0008-5472.CAN-15-0037

\section{Publish your work in this journal}

Cancer Management and Research is an international, peer-reviewed open access journal focusing on cancer research and the optimal use of preventative and integrated treatment interventions to achieve improved outcomes, enhanced survival and quality of life for the cancer patient.
The manuscript management system is completely online and includes a very quick and fair peer-review system, which is all easy to use. Visit http://www.dovepress.com/testimonials.php to read real quotes from published authors. 